\title{
Dispelling the Myth of Work-Related de Quervain's Tenosynovitis
}

\author{
John C. Dunn, MD ${ }^{1}$ Michael M. Polmear, MD ${ }^{1}$ Leon J. Nesti, MD, PhD² \\ ${ }^{1}$ Department of Orthopaedic Surgery, William Beaumont Army \\ Medical Center, El Paso, Texas \\ 2 Department of Surgery, Uniformed Services University, Bethesda, \\ Maryland \\ Address for correspondence Michael M. Polmear, MD, Department of \\ Orthopaedic Surgery, William Beaumont Army Medical Center, 5005 N \\ Piedras St, El Paso, TX 79920 (e-mail: michael.polmear@gmail.com).
}

J Wrist Surg 2019;8:90-92.

\author{
Abstract \\ Keywords \\ - de Quervain's \\ tenosynovitis \\ - occupation \\ - repetitive \\ - cumulative trauma \\ - disorder
}

De Quervain's Tenosynovitis (DQT) is a common condition characterized by pain about the dorsal-radial aspect of the wrist, just proximal to the radial styloid. The condition is precipitated by a thickened first dorsal compartment and its tendons. The impression that DQT is caused from work-related injury is misdirected, as no study has established an association between hand usage at work or trauma with DQT. Physicians should exercise caution when discussing the causes and natural history of DQT with symptomatic patients.
Initially described in the late 19th century, de Quervain's tenosynovitis (DQT) is a common condition that causes pain around the dorsoradial aspect of the wrist, just proximal to the radial styloid. ${ }^{1}$ The condition is precipitated by a thickened first dorsal compartment and its tendons, the abductor pollicis longus (APL), and the extensor pollicis brevis (EPB). ${ }^{2}$ These symptoms may be associated with lost work and secondary gain from workmen's compensation litigation. ${ }^{3}$ In fact, there are now legal counsels that advertise as "repetitive stress injury attorneys." Injury lawyer Web sites claim that DQT produces "career-ending disability" and advertise cases in which they won tens of thousands of dollars for perceived work-related cases. However, the belief that DQT is caused by work-related injury is misdirected, as no study has established an association between hand usage at work or trauma with DQT. ${ }^{4,5}$ This erroneous conviction may be precipitated by a system of workmen's compensation that pays individuals not to work.

The extensor retinaculum is thickened in DQT but not from an inflammatory or traumatic work related process. Instead, the first dorsal compartment undergoes metaplastic change with thickened, less vascular, synovial layers and may ultimately be three to four times thicker than normal. ${ }^{6}$ In addition, the first dorsal compartment experiences a decreased cross-sectional area. An analysis of biopsy samples taken from patients with DQT undergoing first dorsal compartment release found that the histopathology of APL and EPB tendon sheaths was characterized by myxoid degeneration with dense fibrous tissue and mucopolysaccharide accumulation. ${ }^{7}$ The authors postulated that these changes were consistent with an intrinsic degenerative mechanism rather than an inflammatory etiology, thus questioning the nomenclature of tenosynovitis. This narrow, morphologically abnormal first dorsal compartment causes impingement and compression of the APL and EPB. This, in turn, increases the tensile load of the irregular retinaculum, stimulates nociceptors, and causes pain. . $2,8-12^{2}$

Cadaveric analyses have determined that an additional septum within the first dorsal compartment is present in 34 to $44 \%$ of individuals. ${ }^{13,14}$ Subcompartmentalization has been reported to be as high as 86 to $94 \%$ in patients with DQT and is often found bilaterally. Additionally, variable numbers of APL and EPB tendon slips have been observed in cadaveric and control wrists. The authors of a large meta-analysis comparing 1,901 normal cadaver specimens and 470 wrists surgically treated for DQT postulated that the variable tendinous insertions affect the degree of constriction within the compartment. ${ }^{14}$ This frequently abnormal constrictive anatomy may be received

October 2, 2018

accepted after revision

December 21, 2018

published online

January 29, 2019
Copyright $\odot 2019$ by Thieme Medical

Publishers, Inc., 333 Seventh Avenue, New York, NY 10001, USA.

Tel: +1(212) 584-4662.
DOI https://doi.org/ 10.1055/s-0039-1677741. ISSN 2163-3916. 
the solitary culprit in precipitating degenerative changes in the first dorsal compartment tendon sheaths and developing DQT symptoms. ${ }^{5,15-18}$

In another analysis, wrists with DQT underwent a diagnostic ultrasound of the wrist extensor compartments before the first dorsal compartment release. Subcompartmentalization was present in $73 \%$ of the first dorsal compartments. The study demonstrated that the vast majority of patients undergoing DQT release have predisposing compressive anatomy and that ultrasound was $100 \%$ sensitive in the diagnosis of subcompartmentalization. ${ }^{19}$ An absence of subcompartmentalization on ultrasound may be a useful adjunct to exclude patients from a diagnosis of DQT and operative management if there is clinical suspicion for secondary gain.

In addition to anatomical factors, patient factors may also be associated with DQT. Those with DQT have high rates of both anxiety and depression, ${ }^{20}$ are more likely to be parttime workers, ${ }^{4}$ and there may be a genetic predisposition. ${ }^{21}$ Stenosing tendonitis of the finger flexor tendons is found more often in patients with DQT. ${ }^{4}$ DQT is 10 times more common in females $2,5,22$ and is often noted in the postpartum period. ${ }^{23,24}$ Finally, patients who undergo surgical treatment for DQT are more likely to have Medicaid insurance, psychiatric illness, and a disabled work status. ${ }^{25}$

While there are many nonmodifiable factors that contribute to DQT, modifiable (work-related) factors have not been identified as risk factors in large series. One case-control analysis compared 189 patients with DQT and 198 control patients without DQT. ${ }^{5}$ While DQT patients were more likely to be older ( 52 vs. 43 years) and female ( 76 vs. 33\%), there was no difference in the groups with regard to the rate of manual labor profession (18 vs. 26\%), medical comorbidities, wrist trauma, computer work, or repetitive forceful work. In fact, patients in the DQT cohort worked 4 hours less than those in the control cohort per week (34 vs. 38 hours) and were less likely to complain of morning wrist stiffness. The authors concluded that neither heavy manual labor nor trauma could be considered a cause of DQT. Furthermore, a systematic review and meta-analysis including 80 articles comprising automechanics, garment workers, shoe assemblers, and meat packers determined that there was no causal relationship between occupational risk factors and DQT. ${ }^{4}$ Furthermore, a prospective analysis of 598 French industrial workers employed in repetitive labor completed a self-administered questionnaire and underwent a physical examination at one point and again 3 years later. While psychosocial factors and personal factors contributed to wrist tendonitis, the nature of the physical work was not identified as a risk factor. ${ }^{22}$

In Finkelstein's original 24 patient survey from 1930, only one patient was a factory worker. Upon surgical exploration, this individual had subsheaths within his first dorsal compartment. ${ }^{10}$ It is possible that work-related activity may cause discomfort to the patient with DQT already or one who has the nonmodifiable risk factors that may predispose DQT. However, it is far less likely that work-related activity itself is the primary cause of DQT. ${ }^{26}$ Just as riding an exercise bike does not cause stenosis of the coronary arteries and its associated symptoms, repetitive work or trauma does not cause DQT. ${ }^{26}$ Physicians should exercise caution when discussing the causes and natural history of DQT with symptomatic patients.

Note

The views expressed in this publication are those of the authors and do not reflect the official policy or position of the Department of the Army, Defense Health Agency, or the US Government.

Conflict of Interest

None declared.

\section{References}

1 de Quervain F. Über das Wesen und die Behandlung der stenosierenden Tendovaginitis am Processus styloideus radii. Münch Med Wschr 1912;59:5-6

2 Moore JS. De Quervain's tenosynovitis. Stenosing tenosynovitis of the first dorsal compartment. J Occup Environ Med 1997;39(10): 990-1002

3 Best TJ. Post-traumatic stenosing flexor tenosynovitis. Can J Plast Surg 2003;11(03):143-144

4 Stahl S, Vida D, Meisner C, et al. Systematic review and metaanalysis on the work-related cause of de Quervain tenosynovitis: a critical appraisal of its recognition as an occupational disease. Plast Reconstr Surg 2013;132(06):1479-1491

5 Stahl S, Vida D, Meisner C, Stahl AS, Schaller HE, Held M. Work related etiology of de Quervain's tenosynovitis: a case-control study with prospectively collected data. BMC Musculoskelet Disord 2015;16:126

6 Ilyas AM, Ast M, Schaffer AA, Thoder J. De Quervain tenosynovitis of the wrist. J Am Acad Orthop Surg 2007;15(12):757-764

7 Clarke MT, Lyall HA, Grant JW, Matthewson MH. The histopathology of de Quervain's disease. J Hand Surg Br 1998;23 (06):732-734

8 Flörcken H. Zur Frage der stenosierenden Tendovaginitis am Processus styloideus radii (deQuervain). München Med Wochenschr 1912;59:1378

9 Patterson DC. DeQuervain's disease: stenosing tendovaginitis at the radial styloid. N Engl J Med 1936;214:101-102

10 Finkelstein $\mathrm{H}$. Stenosing tendovaginitis at the radial styloid process. J Bone Joint Surg Am 1930;12:509-540

11 Stein HC. Stenosing tendovaginitis. Am J Surg 1927;3:77-78

12 Younghusband OZ, Black JD. DeQuervain's disease: stenosing tenovaginitis at the radial styloid process. Can Med Assoc J 1963; 89:508-512

13 Leslie BM, Ericson WB Jr, Morehead JR. Incidence of a septum within the first dorsal compartment of the wrist. J Hand Surg Am 1990;15(01):88-91

14 Lee ZH, Stranix JT, Anzai L, Sharma S. Surgical anatomy of the first extensor compartment: a systematic review and comparison of normal cadavers vs. De Quervain syndrome patients. J Plast Reconstr Aesthet Surg 2017;70(01):127-131

15 El-Hadidy S, Badran D, Sirhan YS, Ababneh M, Doar H. De Quervain's tendovaginitis stenosans in Jordanians. Jordan Med J 2006;40(03):179-183

16 Gonzalez MH, Sohlberg R, Brown A, Weinzweig N. The first dorsal extensor compartment: an anatomic study. J Hand Surg Am 1995; 20(04):657-660

17 Minamikawa Y, Peimer CA, Cox WL, Sherwin FS. De Quervain's syndrome: surgical and anatomical studies of the fibroosseous canal. Orthopedics 1991;14(05):545-549

18 Shiraishi N, Matsumura G. Anatomical variations of the extensor pollicis brevis tendon and abductor pollicis longus tendonrelation to tenosynovectomy. Okajimas Folia Anat Jpn 2005;82(01): 25-29 
92 Work-Related de Quervain's Tenosynovitis Dunn et al.

19 Choi SJ, Ahn JH, Lee YJ, et al. de Quervain disease: US identification of anatomic variations in the first extensor compartment with an emphasis on subcompartmentalization. Radiology 2011;260(02): 480-486

20 Beleckas CM, Wright M, Prather H, Chamberlain A, Guattery J, Calfee RP. Relative prevalence of anxiety and depression in patients with upper extremity conditions. J Hand Surg Am 2018;43(06): 571.e1-571.e8

21 Kim SK, Ahmed MA, Avins AL, Ioannidis JPA. A genetic marker associated with de Quervain's tenosynovitis. Int J Sports Med 2017;38(12):942-948

22 Leclerc A, Landre MF, Chastang JF, Niedhammer I, Roquelaure Y; Study Group on Repetitive Work. Upper-limb disorders in repetitive work. Scand J Work Environ Health 2001;27(04): 268-278

23 Johnson CA. Occurrence of de Quervain's disease in postpartum women. J Fam Pract 1991;32(03):325-327

24 Schumacher HR Jr, Dorwart BB, Korzeniowski OM. Occurrence of de Quervain's tendinitis during pregnancy. Arch Intern Med 1985; 145(11):2083-2084

25 Kazmers NH, Liu TC, Gordon JA, Bozentka DJ, Steinberg DR, Gray BL. Patient- and disease-specific factors associated with operative management of de Quervain tendinopathy. J Hand Surg Am 2017; 42(11):931.e1-931.e7

26 Kay NR. De Quervain's disease. Changing pathology or changing perception? J Hand Surg Br 2000;25(01):65-69 